\title{
Identificación de Escherichia Coli presente en alimentos preparados en los comedores populares del distrito de Chaclacayo, Lima, Perú
}

\author{
Identification of Escherichia Coli in foods prepared in Public Kitchens of Chaclacayo District, Lima, Perú
}

\author{
Annie Bell Zenteno Guerra ${ }^{1}$, Noemí Caruajulca Pérez², Félix Palacios Morales³
}

\begin{abstract}
RESUMEN
Objetivo: Identificar la presencia de E. Coli en alimentos preparados en los comedores populares del distrito de Chaclacayo, Lima. Material y Métodos: Se realizó un estudio experimental de diseño longitudinal, donde la muestra estuvo conformada por 15 comedores populares cuyo muestreo fue no probabilístico. Los instrumentos que se utilizaron fueron las placas Petrifilm y equipos de laboratorio para la recolección y análisis de los alimentos preparados. Para el proceso estadístico se utilizó la planilla de Microsoft Office Excel 2010, aplicando las medidas de tendencia central. Resultados: De los comedores estudiados, $3(21.4 \%)$ de ellos tuvieron presencia de E. Coli. De las 42 muestras analizadas, en $5(12 \%)$ de ellas se identificó la presencia de E. Coli, de las 5 muestras con E. Coli positivo el $60 \%$ fueron encontradas en guisos y el $40 \%$ en infusiones al comparar la presencia de esta bacteria en los alimentos preparados, según las normas de inocuidad sanitaria para el consumo humano. Conclusiones: El 21\% de los comedores fueron considerados rechazables y el $79 \%$ aceptables.
\end{abstract}

Palabras clave: Comedores populares, Escherichia Coli, inocuidad sanitaria, Petrifilm, alimentos preparados.

\section{SUMMARY}

Objective: The objective of this study was to identify the presence of $E$. Coli in foods prepared in the kitchens Chaclacayo District, Lima. Methods: An experimental study was longitudinal design where the sample consisted of 15 soup kitchens and was non-probability sampling. The instruments used were Petrifilm plates and laboratory equipment for the collection and analysis of prepared foods. For statistical process worksheet used Microsoft Office Excel 2010, using measures of central tendency. Results: From the dining studied, 3 (21.4\%) of them had the presence of E. Coli. Of the 42 samples tested, in $5(12 \%)$ of which identified the presence of $E$. Coli, of the 5 samples with E. Coli positive $60 \%$ were found in stews and $40 \%$ in infusions when comparing the presence of this bacterium in food preparations, as health safety standards for human consumption. Conclusions: It was concluded that $79 \%$ of the kitchens were considered acceptable and $21 \%$ objectionable.

Keywords: Popular dining, Escherichia Coli, health safety, Petrifilm, food prepared.

\footnotetext{
${ }^{1}$ Asistente de Laboratorio de la EAP Nutrición, Universidad Peruana Unión, Lima, Perú.

${ }^{2}$ Nutricionista de Seguros Rímac, sede San Isidro, Perú.

3 Jefe de Laboratorio de Microscopía de la Universidad Peruana Unión, Lima, Perú.
} 


\section{INTRODUCCIÓN}

Varios autores han estudiado los alimentos servidos en los comedores populares desde el punto de vista nutricional - alimentario, así como su valor estratégico, como parte de las políticas sociales del Estado. Por el contrario, no parecen haberse realizado estudios de la inocuidad de los alimentos servidos, desde el punto de vista microbiológico. En ese sentido, un alimento se considera inocuo según la carencia de agentes patógenos; es decir, cuando las concentraciones de productos tóxicos, toxinas microbianas y microorganismos patógenos no superan los valores máximos permitidos.

Los alimentos en ocasiones pueden vehiculizar microorganismos patógenos. Son muchas las bacterias que provocan procesos diarreicos por el consumo de alimentos contaminados. Estas tienen la capacidad de producir toxinas o invadir la mucosa intestinal, entre ellas se encuentra la $E$. Coli. Las vías de transmisión más comunes para $E$. Coli son el agua, los productos cárnicos, lácteos, así como frutas, verduras y hortalizas mal lavadas, o lavadas con agua contaminada.

Solo en Lima, los comedores populares proporcionan alimentación diaria a medio millón de personas que buscan el apoyo mutuo para superar la pobreza, la cual llega a impedirles el acceso a una alimentación mínima. Este es un servicio organizado por el Estado (por conducto de los ministerios de bienestar social o educación), por iniciativas particulares o por autogestión de la comunidad.

Los alimentos preparados y servidos sin criterios de control microbiológico representan para la salud pública posibles riesgos que son necesarios conocer y prevenir. En el Perú, no hay estudios específicos respecto a este tema, siendo necesaria una evaluación de la situación real de la calidad de alimentos que sirven al consumidor. El presente trabajo tiene como objetivo determinar la presencia de Escherichia Coli en alimentos preparados en los comedores populares del distrito de Chaclacayo.

\section{MATERIALES Y MÉTODOS}

Se realizó un estudio experimental de diseño longitudinal mediante cultivos microbiológicos en placas Petrifilm para evaluar la presencia de E. Coli. La investigación se llevó a cabo en los comedores populares del distrito de Chaclacayo, ubicados entre los Km 19.5 a 23 de la Carretera Central, en el departamento de Lima. El distrito de Chaclacayo tiene una población de 41110 personas de los cuales 1840 son beneficiarios inscritos y asistidos en 23 comedores populares. Por muestreo no probabilístico se eligió 15 comedores que funcionan activamente, de los cuales uno fue retirado por ser inactivo. El número de beneficiarios fue 1200 comensales entre niños, adultos, madres gestantes y personas de la tercera edad. En los criterios de inclusión se consideraron todos los comedores populares que participan activamente en el proyecto ADELANTE de ADRA Perú, excluyendo a los que no están considerados en el proyecto.

Los materiales que se utilizaron para la investigación fueron: frascos estériles, termómetros, hielo, placas Petrifilm, pipetas, peptona, micro pipeta $(1 \mu \mathrm{l})$, cloruro de sodio, agua destilada, espátula estéril, asa de siembra, cubreobjetos, papel aluminio y los equipos fueron: estufa de incubación, microscopio, cámara de Neubauer, pipeteador, balanza de alimento, autoclave.

Para la recolección de muestras se utilizaron frascos estériles etiquetados con la fecha, tipo de muestras, lugar de muestreo y nombre del analista. El frasco fue cerrado herméticamente y almacenado en un cooler a una temperatura de $10^{\circ} \mathrm{C}$ para ser transportado al laboratorio de Biología de la Facultad de Ciencias de la Salud de la Universidad Peruana Unión, para así realizar el análisis microbiológico correspondiente. Se sistematizó la toma de muestra de tres comedores por día, considerando los horarios oportunos entre las 11:00 am a 12:30 pm. Por cada comedor se tomó 3 muestras, una muestra de guiso, una de sopa y una de infusión, haciendo un total de 42 muestras.

La técnica utilizada para la determinación de $E$. Coli por medio de placas Petrifilm, para la preparación de la muestra y siembra por dilución tuvo el siguiente procedimiento:

- Se utilizó placas Petrifilm para E. Coli.

- Se esterilizaron los materiales para la siembra por dilución.

- Se codificó los tubos de ensayo y se enumeró del 1 al 2, luego en cada uno se colocó 9 ml de solución salina peptonada.

- Se pesó 1 gramo de muestra con una espátula estéril en una cubeta de papel aluminio.

- En el tubo de prueba N. 1 se agregó la muestra para realizar la dilución y homogenizarla en la solución peptonada para preparar la solución madre.

- Se agitó la muestra hasta diluir el medio, luego se separó $1 \mathrm{ml}$ de muestra y se incorporó al segundo tubo.

- Se tomó la muestra con una pipeta de 1 a $2 \mathrm{ml}$ para incorporarlo en la placa Petrifilm, luego fue llevada a la estufa de incubación por 48 horas $(+/-2 \mathrm{hrs})$ a $35^{\circ} \mathrm{C}\left(+/-1^{\circ} \mathrm{C}\right)$. 
- Luego de 48 horas se realizó la lectura y descripción de las características para observar con el estereoscopio la presencia de colonias de E. Coli, las cuales fueron ordenadas por código de comedor para hacer el recuento. Cada una de las pruebas, determinaciones y conteos fueron comparados con las tablas de límites microbiológicos permisibles establecidos según las normas de inocuidad.

La técnica para la determinación de E. Coli a través del cálculo de células/ $\mu 1$ en cámara de Neubauer consistió en lo siguiente:

- En un pocillo con ayuda de una micropipeta se colocó $1 \mathrm{ml}$ de solución peptonada.

- Con el asa de siembra esterilizada se tomó una colonia de E. Coli de cada placa Petrifilm, la cual fue colocada en la microgradilla.

- Con una micropipeta se tomó $1 \mu 1$ de la dilución.

- La punta de la micropipeta fue colocada en el borde de la cámara, tratando que el líquido penetre entre la cámara y el cubreobjetos desde el lateral, por capilaridad.

- Posteriormente se colocó la cámara en posición horizontal, sobre la platina, para su observación microscópica.
La fórmula utilizada para el cálculo de la biomasa es la siguiente:

Partículas por $\mu 1$ de volumen

Células

Superficie contada $\left(\mathrm{mm}^{2}\right)$ x Profundidad (mm) x Dilución

Asimismo, se realizó sesiones educativas al personal que manipulaba los alimentos en dichos comedores, realizándose estas con el propósito de aumentar sus conocimientos y fomentar las buenas prácticas higiénicas en sus labores diarias. La sesión educativa se realizó en dos ocasiones, debido a que las socias de todos los comedores no llegaron a la reunión programada. Se pasó control de asistencia. Además, al terminar la exposición se impartieron trípticos informativos referentes al tema; se hizo uso de un rotafolio y cámaras fotográficas para tener un récord de la misma.

La información obtenida sobre la presencia de E. Coli fue vaciada en una planilla de Microsoft Office Excel 2010, los resultados fueron expresados en gráficos circulares y en barras. Para el proceso estadístico se utilizó la misma plantilla con el fin de aplicar el análisis de medidas de tendencia central.

\section{RESULTADOS}

Tabla 1

Identificación de E. Coli en los comedores populares

\begin{tabular}{llll}
\hline \multirow{2}{*}{. $^{\circ}$} & \multicolumn{2}{l}{ Tipo de muestras } & \\
\cline { 2 - 4 } comedor & Guisos & Sopas & Infusiones \\
\hline 01 & - & - & - \\
02 & - & - & - \\
03 & - & - & - \\
04 & - & - & $\checkmark$ \\
05 & $\checkmark$ & - & - \\
06 & - & - & - \\
07 & - & - & - \\
08 & - & - & - \\
09 & $\checkmark$ & - & - \\
10 & - & - & - \\
11 & - & - & - \\
12 & - & - & - \\
13 & - & - & $\checkmark$ \\
14 & $\checkmark$ & - & - \\
\hline
\end{tabular}

En la tabla 1 se observa que de los 14 comedores estudiados, 3 (21.4\%) de ellos tuvieron presencia de E. Coli. 


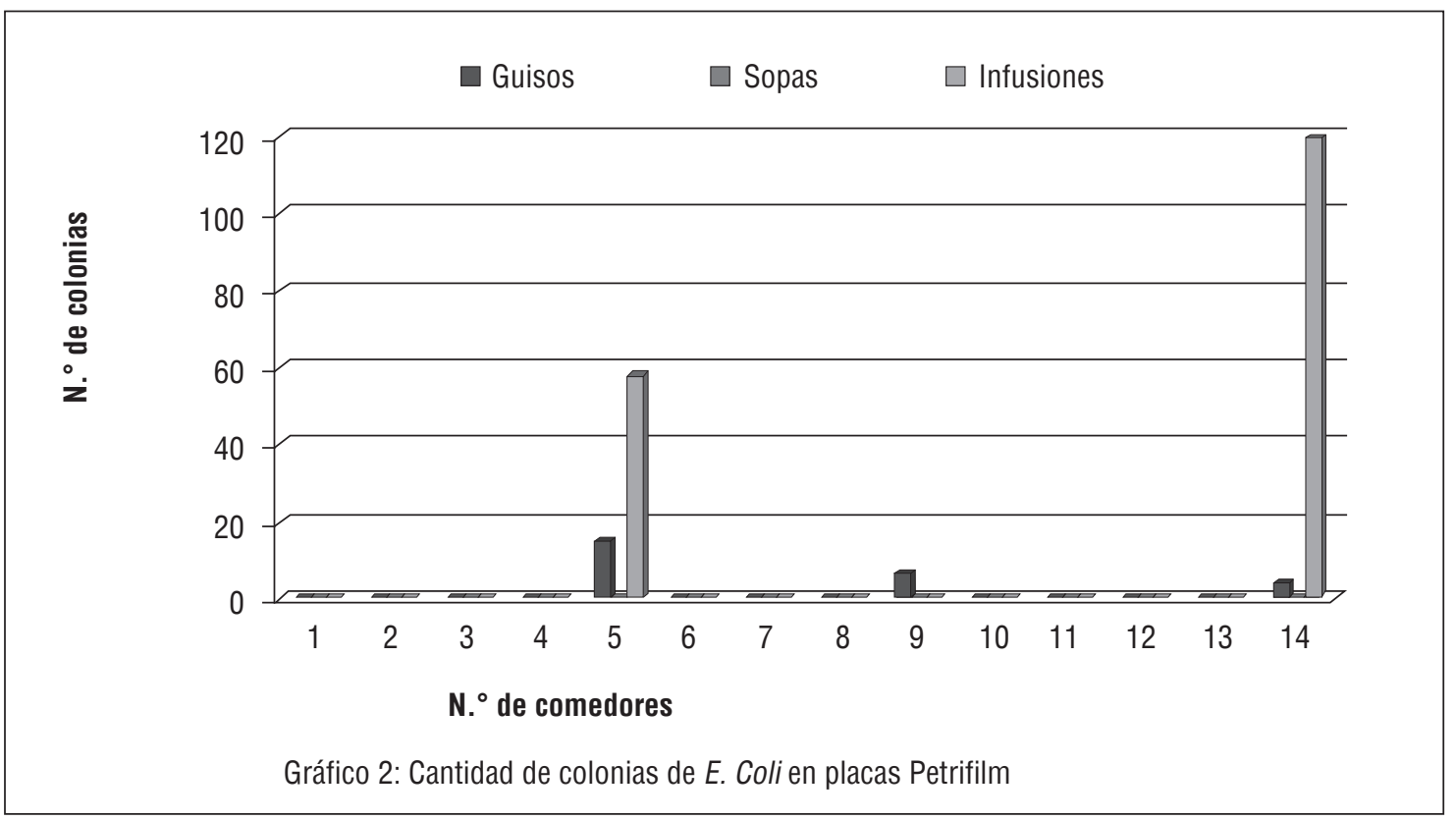

Figura 1.

Cantidad de colonias de E. Coli en placas Petrifilm

En la figura 2 se observan las cantidades de colonias de E. Coli encontradas en las 5 muestras de los comedores populares mediante el uso de las placas Petrifilm, teniendo como resultado un promedio de $40 \mathrm{UFC} / \mathrm{ml}$, un mínimo de $04 \mathrm{UFC} / \mathrm{ml}$ y un máximo de $120 \mathrm{UFC} / \mathrm{ml}$. Además se observa que el comedor con mayor presencia de colonias de E. Coli fue el N. ${ }^{\circ} 14$. Asimismo, de las 42 muestras analizadas, en $5(12 \%)$ de ellas se identificó la presencia de E. Coli, de las 5 muestras con $E$. Coli positivo, el $60 \%$ fueron encontradas en guisos y el $40 \%$ en infusiones.

Tabla 2

Cantidades de colonias (UFC/ml)

\begin{tabular}{lll}
\hline \multirow{2}{*}{ Agente microbiano } & \multicolumn{2}{l}{ Límite por g. o $\mathrm{ml}$} \\
\cline { 2 - 3 } E. Coli & $\mathrm{M}$ & $\mathrm{M}$ \\
\hline
\end{tabular}

En la tabla 2 se muestra que los resultados de las cantidades de colonias (UFC/ml) encontradas en las muestras fueron comparadas con las tablas de la norma sanitaria que establecen los criterios microbiológicos de calidad sanitaria e inocuidad para los alimentos y bebidas de consumo humano. Donde " $m$ " es el límite microbiológico que separa la calidad aceptable de la rechazable y "M", la cantidad que al ser superada es considerada como inaceptable, es decir, que el alimento representa un riesgo para la salud.

Luego se procedió a comparar las cantidades encontradas con las establecidas, donde el $78.6 \%$ de los comedores fueron considerados aceptables y el $21.4 \%$ fueron rechazados.

\section{DISCUSIÓN}

La salud es un estado completo de bienestar físico, mental y social, y no solo la ausencia de molestias o enfermedades físicas. Por ello, una buena alimentación supone un factor determinante para mantener y mejorar nuestra salud y, por supuesto, prevenir que los alimentos, que tenemos a nuestro alrededor, se contaminen sería otra forma de evitar enfermedades. $\mathrm{Si}$ tenemos una correcta higiene 
alimentaria conseguiremos evitar gran número de enfermedades y alteraciones en los alimentos. Por tanto, la higiene alimentaria es el conjunto de medidas necesarias para asegurar la inocuidad de los alimentos desde que se obtienen hasta que llegan al consumidor final.

Al identificar la presencia de E. Coli en alimentos preparados en los comedores populares se encontró que el $21 \%$ de ellos tuvo presencia de esta bacteria. En este sentido, el fin de los comedores populares es elevar el nivel alimentario y nutricional de la población pobre y en extrema pobreza, ejecutando acciones de apoyo y de seguridad alimentaria; por lo tanto, las entidades municipales y responsables directos deben dar mayor importancia a la seguridad alimentaria para no exponer a los consumidores a desencadenar infecciones intestinales y no dar mal uso al presupuesto invertido en dicha población.

Para lograr la seguridad alimentaria, se debe tener en cuenta la capacitación continua a los manipuladores de alimentos, debido a que esta es fundamental para cualquier sistema de gestión de inocuidad de alimentos. La capacidad que tenga un establecimiento de alimentos para alcanzar la inocuidad y la aptitud de los alimentos depende, en gran medida, de la capacitación del personal. Si se comprueba que su conocimiento es insuficiente para garantizar la higiene y el proceso de manufactura, entonces cualquier persona que intervenga en las tareas relacionadas con los alimentos representa una posible amenaza para la inocuidad de los productos. La capacitación debe planificarse y organizarse en función de los objetivos que se quieren lograr. No hacerlo constituye un error que puede tener graves consecuencias en la inocuidad y la aptitud del producto.

Al identificar la presencia de E. Coli, se encontraron cantidades que sobrepasaban los límites permitidos en alimentos expuestos a temperaturas térmicas $(<3 \mathrm{UFC} / \mathrm{g}$ ) en un $12 \%$ del total de muestras, encontrados en 3 guisos y 2 infusiones.

Las bacterias se reproducen en una amplia variedad de temperaturas, pero a temperaturas cercanas a las del cuerpo humano alcanzan su mayor reproducción. Por eso, los alimentos a temperatura ambiente permiten un rápido crecimiento de bacterias $\mathrm{y}$ tienen mayor riesgo de producir enfermedades. En general se considera que por debajo de los $5^{\circ} \mathrm{C}$ o por arriba de $\operatorname{los} 60^{\circ} \mathrm{C}$, la reproducción de las bacterias es muy escasa o casi nula. Dadas las condiciones del tipo de alimento, la humedad y la temperatura, algunas bacterias pueden dividirse en dos cada 20 minutos. Si se da el tiempo suficiente, es posible que un pequeño grupo de bacterias se incremente hasta alcanzar un número importante, capaz de causar enfermedades. Por esa razón, es esencial que los alimentos de alto riesgo no permanezcan a la temperatura de la zona de peligro más de lo necesario. Los alimentos deben alcanzar una temperatura de $70^{\circ} \mathrm{C}$ para que su inocuidad esté garantizada. Una temperatura de $70^{\circ} \mathrm{C}$ mata incluso altas concentraciones de microorganismos en 30 segundos. Entonces, encontrar colonias de E. Coli en alimentos expuestos a temperaturas térmicas puede deberse a que estos no fueron cocinados completamente o que, después de haber sido cocinados, no se los mantuvo a la temperatura apropiada ocasionando, de esta forma, un rápido crecimiento de las bacterias.

Al considerar el estudio sobre análisis microbiológico de alimentos en un centro de atención a ancianos, por Chávez Alas P. y Reinosa Mendoza $\mathrm{K}$ (2011), tuvieron resultados de contaminación de $E$. Coli en el $60 \%$ de los alimentos analizados, a diferencia de nuestro estudio se encontraron porcentajes menores de $E$. Coli, esto se debe a que los alimentos, dependiendo de la preparación en los que se utilicen, van a requerir de una menor o mayor manipulación para elaborarlos $\mathrm{y}$, tomando en cuenta que los manipuladores no utilizan ninguna clase de guantes durante la manipulación, estos se convierten en portadores del microorganismo en sus manos y pueden fácilmente contaminar cualquier alimento con el que tengan contacto directo.

La presencia de E. Coli en los alimentos no constituye un indicador directo de la presencia de un patógeno, sino que implica únicamente un cierto riesgo de que pudiera estar presente. Al ser un huésped constante del intestino del hombre y de los animales de sangre caliente, se considera como un buen indicador de contaminación fecal. Tiene el inconveniente de vivir poco tiempo fuera del intestino, por lo que su presencia en los alimentos indica contaminación fecal reciente. Recuentos elevados de estos microorganismos en los alimentos sugieren una falta general de limpieza en los mismos, en los utensilios y un almacenamiento inadecuado. Se destruye con facilidad a temperatura de pasteurización y mediante la apropiada cocción de los alimentos, así como durante su almacenamiento en frío.

Por otro lado, según el estudio de la calidad microbiológica de jugos preparados en hogares de bienestar familiar en la zona norte de Cundinamarca, por Ávila P. y Fonseca M. (2008), se analizaron muestras de jugos y de agua potable encontrando que el $23.3 \%$ de los jugos y el $20 \%$ del agua presentaban contaminación por E. Coli, demostrando que la fuente de contaminación principal de los jugos fue el 
agua. En comparación a nuestro estudio, se encontró que el $40 \%$ de las muestras contaminadas con E. Coli fueron infusiones, poniendo en evidencia que este es un factor crítico para la calidad de las bebidas con o sin tratamiento térmico y posiblemente pueda ser una fuente de enfermedades diarreicas. Además, la presencia de E. Coli en el agua es un indicio de contaminación fecal reciente, por lo que tras su detección debería considerarse la toma de medidas adicionales, como la realización de muestreos adicionales y la investigación de las posibles fuentes de contaminación, como un tratamiento inadecuado o alteraciones de la integridad del sistema de distribución; sin olvidar también que los recipientes de almacenamiento como baldes o jarras para las bebidas con o sin tratamiento térmico pueden estar siendo lavados con agua contaminada con esta bacteria. Uno de los factores que se observó al visitar los diferentes establecimientos es que toda la vajilla y utensilios se enjuagan en la misma agua, esto hace que los microorganismos puedan multiplicarse.

Para los resultados obtenidos en este estudio se utilizaron las placas Petrifilm las cuales tienen un medio de cultivo VRB, un agente gelificante soluble en agua fría, indicador de actividad Glucoronidasa y un tinte indicador que facilita la enumeración de las colonias de coliformes totales y de E. Coli. En otros estudios como el de alimentos preparados con chorizos, listos para el consumo, mediante la investigación de coliformes y salmonella en la ciudad de El Alto, Bolivia, por Ramos K. (2006), se utilizó el medio de cultivo agar EMB el cual es utilizado para el aislamiento selectivo de bacilos gram negativos debido a que permite el rápido desarrollo y escasas exigencias nutricionales de todas las especies de la familia Enterobacteriaceae. En el estudio de análisis microbiológico de alimentos que se preparan y consumen en el centro de atención a ancianos "Sara Zaldívar", para la identificación de E. Coli se utilizó como medio de cultivo el agar Chromocult, un medio selectivo para la detección simultánea y recuento de colonias de coliformes totales y E. Coli en los alimentos no elaborados, así como muestras de agua superficial. Otros estudios utilizan diferentes medios de cultivo; esto hace que haya una cierta variación en los resultados obtenidos para la identificación de $E$. Coli debido a que los medios de cultivo por el tipo de composición que tienen van a hacer que haya un mayor o menor desarrollo de colonias de E. Coli, otro factor que va a influir en el crecimiento de colonias va hacer el número de diluciones que se le realice a la muestra para hacer la siembra de la misma.

En el estudio microbiológico y condiciones sanitarias de los comedores no permanentes en
Albacate, por Pedregal (2000), se encontró que más del $75 \%$ de los establecimientos presentaban deficiencias estructurales, siendo relevante la falta de espacio en la cocina. Así también, encontramos en nuestro estudio que el $21 \%$ de los comedores se ubicaron en una categoría rechazable debido a que presentaban deficiencias en la estructura, almacenamiento y manipulación de alimentos, siendo relevante la mala distribución de las áreas de preparación de los alimentos, esto indica un riesgo potencial de contaminación cruzada.

De la gran mayoría de comedores sus instalaciones difícilmente se adecúan a las recomendaciones de las BPM, limitación que puede convertirse en un factor clave para el logro de la inocuidad de los productos. De ahí la importancia de que las directivas de cada comedor conozcan los requisitos mínimos que debe cumplir el establecimiento, para que lo vayan acondicionando progresivamente y puedan lograr el objetivo de la inocuidad, aunque los recursos sean limitados.

En la investigación solo se tomó en cuenta el estudio de E. Coli, sin embargo, es importante mencionar que en la mayoría de muestras analizadas se identificó la presencia de coliformes totales, los cuales sobrepasaban los límites microbiológicos establecidos según las normas de inocuidad. La presencia de estas bacterias nos informan que hubo mala calidad higiénica en el proceso de preparación de los alimentos, falta de higiene de los manipuladores o recontaminación después del proceso, una contaminación con materia fecal humana-animal o una contaminación con desechos o residuos en descomposición; también, se identificó la presencia de microorganismos patógenos como Salmonella spp. la cual representa un potencial peligro para la salud de los consumidores.

Por lo expuesto, se ha identificado que sería conveniente utilizar estos resultados para observar la relación que existe entre otras variables como, por ejemplo, la enfermedad diarreica aguda en niños, estado nutricional de los consumidores o alguna otra variable de interés para poder intervenir en la población beneficiaria.

En conclusión de los 14 comedores estudiados, 3 $(21.4 \%)$ de ellos tuvieron presencia de E. Coli. De las 42 muestras analizadas, en $5(12 \%)$ de ellas se identificó la presencia de $E$. Coli, de las 5 muestras con E. Coli positivo el $60 \%$ fueron encontradas en guisos y el $40 \%$ en infusiones. A través de las placas Petrifilm se determinó un mínimo de $04 \mathrm{UFC} / \mathrm{ml}$, un máximo de $120 \mathrm{UFC} / \mathrm{ml}$ y un promedio de $40 \mathrm{UFC} / \mathrm{ml}$ de E. Coli, encontrándose que el comedor con mayor 
Identificación de Escherichia coli presente en alimentos preparados en los Comedores Populares del Distrito de Chaclacayo, Lima, Perú

presencia de colonias de E. Coli fue el N. ${ }^{\circ} 14$. Al hacer el conteo en cámara de Neubauer se determinó un mínimo de $8181818 \mathrm{cel}$. $/ \mathrm{ml}$, un máximo de 46 $818181 \mathrm{cel} . / \mathrm{ml}$ y en promedio se encontraron 19 $181799 \mathrm{cel}$. /ml de E. Coli. Y el comedor con mayor presencia de células de E. Coli fue el N. ${ }^{\circ} 5$.

Al comparar la presencia de E. Coli en alimentos preparados en los comedores populares según las normas de inocuidad sanitaria para el consumo humano se encontró que el $79 \%$ de los comedores son considerados aceptables y el $21 \%$ son rechazables.

\section{Declaración de financiamiento y de conflicto de intereses:}

El estudio fue financiado por la autora, quien declara no tener algún tipo de conflicto de interés en la investigación realizada.

\section{Correspondencia:}

Lic. Annie Bell Zenteno Guerra

Correo electrónico: vale_1803@hotmail.com

\section{REFERENCIAS BIBLIOGRÁFICAS}

Arango J, Silvestre A, López C. (1997). Condiciones sanitarias de los comedores comunitarios del conurbano de Buenos Aires, Argentina. Revista Panamericana de la Salud, Argentina; 02: 225-231.

Ávila Pineda G. T. (2008). Fonseca Moreno M. M. Calidad microbiológica de jugos preparados en hogares de bienestar familiar en la zona norte de Cundinamarca. [Tesis de grado]. Bogotá, Colombia: Pontificia Universidad Javeriana.

Barrero Gozalo B. (2013). Manipulación de alimentos. España. Recuperado en: https://coformacion.com/ manuales/manual-manipulador-de-alimentoscoformacion.pdf

Bell C., Alec K. (2000). E. Coli. Una aproximación práctica al microorganismo y su control en los alimentos. Zaragoza, España: Editorial ACRIBIA, S.A.

Bueno Cortés M. J. (2006). La higiene intestinal: España: Zaragosa S.A.

Censos Nacionales 2007: XI de población y VI de vivienda [en línea]. Perú: INEI, 2007 [Consulta: 29 enero 2013]. Disponible en: http://desa.inei.gob.pe/censos2007/ tabulados/?id=ResultadosCensales

EsSaludd. Enfermedades diarreicas agudas: GCPS/ OPIS; 2012 Recuperado en: http://www.essalud.gov.pe/ noticias/boletinepidemi_2012_2.pdf

García Moreno A. M. (2012). Evaluación de la calidad microbiológica de bocaditos fritos a base de papa (solanum tuberosum) que se elaboran y expenden en forma artesanal en la Urb. Ciudad del Pescador, Distrito Bellavista-Callao. [Proyecto de investigación]. Perú: Universidad Nacional del Callao.

Instructivo técnico de análisis/ensayo para recuento de coliformes y E. Coli. Mediante técnica Petrifilm. (2005). Chile: Gobierno de Chile, 2005. Recuperado en:http://historico.sag.gob.cl/common/asp/ pagAtachadorVisualizador.asp? $\arg$ CryptedData $=3275$

Montville Thomas J, Matthews Karl R. (2009). Microbiología de los alimentos: introducción. España: Editorial ACRIBIA, S.A.
Organización Mundial de la Salud (OMS). (2013). Buenas Prácticas Higiénicas. Manual sobre las cinco claves para la inocuidad de los alimentos. 2007. Recuperado en: www.who.int/consumer/manual_keys_es.pdf

Organización Panamericana de la Salud. (1990). Estudio sobre intervenciones alimentario-nutricionales para poblaciones de bajos ingresos en Latinoamérica y el Caribe. Washington, DC: OPS. Recuperado en:http:// www2.paho.org/hq/dmdocuments/2009/ReunionSudamericana-Alimentacion-Nutricion-Nino-Pequeno. pdf

Organización Panamericana de la Salud. (2009). Problemas nutricionales en países en desarrollo en las décadas de 1980 y 1990: simposio patrocinado por el Consejo Nacional de Investigaciones (EUA). Washington, DC: OPS; 1987 [actualizada 19 enero 2009. Recuperado en:http://www2.paho.org/hq/dmdocuments/ MalnutritionSpa.pdf

Ramos Queso E. (2006). Análisis microbiológico de alimentos preparados con chorizos, listos para el consumo, mediante la investigación de coliformes y salmonella en la ciudad de El Alto. [Tesis de Licenciatura]. La Paz, Bolivia: Universidad Mayor de San Andrés.

Resolución Ministerial N.o 591-2008-MINSA [en línea]. Perú; 2008. Recuperado en: http://www.minsa.gob.pe

Smoot LM, Pierson MD. (2000). Microorganismos indicadores y criterios microbiológicos. En: microbiología de los alimentos. Fundamentos y fronteras. Zaragoza, España: Editorial ACRIBIA, S.A.

Zibechi R. (2007). Comedores populares de Perú: contra el hambre y soledad. Recuperado en: http://www. cipamericas.org/es/

Pedregal Castillo F. García Garví M. F., Naharro A \& López F. (2000). Estudio microbiológico y condiciones sanitarias de los comedores no permanentes en Albacete. Rev. Centro de Salud Atalaya, España 2000; 408-416.

Recibido: 28/08/2013

Aceptado: 25/11/2013 